\title{
Utility of Echocardiography in Cardiac Evaluation of COPD Patients and Its Relationship with Severity of Disease
}

\author{
Rambabu Singh ${ }^{1}$, Rajat Jain ${ }^{2}$, Shyam Mohan Yadav ${ }^{3}$ \\ ${ }^{1}$ Department of Internal Medicine, MLB Medical College, Jhansi, Uttar Pradesh, India. \\ ${ }^{2}$ Department of Internal Medicine, MLB Medical College, Jhansi, Uttar Pradesh, India. \\ ${ }^{3}$ Department of Internal Medicine, MLB Medical College, Jhansi, Uttar Pradesh, India.
}

\section{ABSTRACT}

\section{BACKGROUND}

COPD is a leading cause of death and disability worldwide as well as in India. It is a multisystem disorder among which cardiac manifestations are common. Echocardiography provides a rapid, non-invasive, portable, and accurate method to evaluate such changes. We wanted to assess the cardiac changes due to COPD by echocardiography, evaluate the correlation between echocardiographic findings and severity of COPD using GOLD guidelines (2011 updates).

\section{METHODS}

This study was a hospital based cross sectional study conducted in M.L.B. Medical College, Jhansi (U.P.). The study included admitted COPD patients in Internal Medicine Department and T.B. Chest Department. The study was conducted after obtaining permission from the Institutional Ethics Committee and identity of the patients has not been revealed.

\section{RESULTS}

Out of 200 admitted patients, 98 patients had cor pulmonale and were further classified by using GOLD guidelines 2017. Upon comparing FEV1 with mPAP in each group we observed $p$ value of 0.001 which is statistically significant. A positive correlation was also found between duration from onset of the disease and mPAP.

\section{CONCLUSIONS}

By estimating PAP early in the disease process, even in those patients who are not able to perform lung function test correctly due to other co-morbidities, we can determine the progression of the disease and can achieve a better outcome by planning a more appropriate and intense line of management.
Corresponding Author:

Dr. Rajat Jain,

Associate Professor,

Department of Internal Medicine,

MLB Medical College,

Jhansi-284004, Uttar Pradesh, India.

E-mail:abha.jain2811@gmail.com

DOI: $10.14260 / j e m d s / 2020 / 270$

Financial or Other Competing Interests: None.

How to Cite This Article:

Singh $R$, Jain $R$, Yadav SM. Utility of echocardiography in cardiac evaluation of COPD patients and its relationship with severity of disease. J. Evolution Med. Dent Sci. 2020;9(15):1242-1246, DOI: $10.14260 / j e m d s / 2020 / 270$

Submission 04-02-2020,

Peer Review 20-03-2020,

Acceptance 27-03-2020,

Published 13-04-2020.

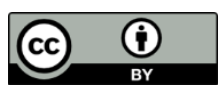

\section{KEY WORDS}

Echocardiography, COPD, Cor Pulmonale, FEV1, mPAP 


\section{BACKGROUND}

COPD is a leading cause of death and disability worldwide. In India, COPD is the second most common lung disorder after pulmonary tuberculosis and remains a major public health problem. COPD is proven to be a multisystem disorder among which cardiac manifestation are most common. Echocardiography provides a rapid, non-invasive, portable, and accurate method to evaluate the cardiac changes.[1]

Cor pulmonale was classically defined as "hypertrophy of the right ventricle resulting from diseases affecting the function and/or structure of the lungs except when these pulmonary alterations are the result of diseases that primarily affect the left side of the heart" (WHO expert committee report)[2]. Since this definition does not indicate the presence of right heart failure, and since the presence of edema does not always imply underlying right heart failure in stable COPD patients, the terms cor pulmonale and right heart failure are not synonymous Pulmonary hypertension (PH) however is always the underlying pathologic mechanism for right ventricular hypertrophy in cor pulmonale. Pulmonary hypertension in COPD is placed in group 3 of the 2003 WHO classification of PH (Rubin 2004),[3] i.e, PH associated with disorders of the respiratory system and/or hypoxemia. $\mathrm{PH}$ associated with lung disease is defined as resting mean PAP (mPAP) greater than $20 \mathrm{~mm} \mathrm{Hg}$ (Weitzenblum 2003),[4] which is different from the definition of primary pulmonary hypertension (mPAP _25 mm Hg).

Chronic obstructive pulmonary disease (COPD) has considerable effects on cardiac functions, including those of the right ventricle, left ventricle, and pulmonary blood vessels. COPD is associated with significant extrapulmonary (systemic) effects among which cardiac manifestations are most common. Most of the increased mortality associated with COPD is due to cardiac involvement. Echocardiography provides a rapid, noninvasive, portable, and accurate method to evaluate the cardiac changes.

Prevalence of Smoking is very high in the region of Bundelkhand in central India and so is the prevalence of COPD. Since the morbidity and mortality is very high due to COPD and its complications, identifying the complications early in the disease will lead to a major reduction in morbidity and mortality and will also contribute to reduction in the economic burden of disease as well. Pulmonary hypertension due to COPD is one of the most important known complications resulting in recurrent hospitalizations and adds to the acceleration of disease activity leading to higher mortality.

\section{Objectives}

- To assess the cardiac changes due to COPD by echocardiography.

- $\quad$ To find out the association between echocardiographic findings and severity of COPD using GOLD guideline (2011 updates).

- To assess the severity of COPD using ABCD assessment tool 2017 GOLD guidelines.

\section{METHODS}

This study was a hospital based cross sectional study conducted in M.L.B. Medical College, Jhansi (U.P.) from Dec. 2017 to August 2019. The study included admitted COPD patients in Internal Medicine Department and T.B. Chest Department. The study was conducted after obtaining permission from the Institutional ethics committee and the identity of the patients would not be revealed.

\section{Inclusion Criteria}

- Any patient diagnosed with COPD coming to MLB Medical College, Jhansi from Dec.

- 2017 to August 2019 was included in the study.

\section{Exclusion Criteria}

- Congenital heart diseases.

- RHD.

- Pericarditis.

- Pericardial effusion.

- Interstitial lung disease with cor pulmonale.

- Hypertensive heart disease.

- $\quad$ Post TB bronchitis with cor pulmonale.

\section{Methodology}

1. All the patients were investigated by spirometry in Department of T.B. and Chest at M.L.B.

Medical College, Jhansi and were further classified into 4 groups

- $\quad$ Mild COPD (FEV1 $\geq 80 \%$ of predicted)

- moderate $(50 \% \leq \mathrm{FEV} 1<79 \%$ predicted $)$.

- $\quad$ severe $(30 \% \leq \mathrm{FEV} 1<49 \%$ predicted),

- $\quad$ very severe (FEV1 02 29\% predicted)

2. PFT was done by Pulmonary Function Equipment (COSMED, REF C09072-02-99, S/N 2015051137) in Department of T.B. and Chest Diseases, MLB Medical College, Jhansi.

3. Every patient was subjected to complete twodimensional and Doppler echocardiography study by 2D echo machine (Hitachi - Aloka-SN: M-12253LI, Model: Alpha-6) in Cardiology Unit, Medicine Department of MLB Medical College, Jhansi by expert cardiologists using following echocardiographic tools.

a. Systolic Pulmonary artery pressure

b. Right atrial pressure

c. Mean pulmonary artery pressure

d. Right ventricular dimension by using echocardiography.

e. Left ventricular function. Left ventricular function will be assessed by using the following parameters

- $\quad$ EF (ejection fraction): measure of how much end-diastolic value is ejected from LV with each contraction $(56 \%-78 \%)$.

- $\quad$ FS (fractional shortening): it is a percentage change in LV dimension with each LV contraction $(28 \%-44 \%)$.

- $\quad$ LV mass = left ventricular mass (88-224 g).

f. E/A (diastolic filling) 
4. The COPD cases were diagnosed by clinical history, general physical examination, detailed systemic examination and necessary investigations.

5. All the patients of COPD were graded according to ABCD assessment tool 2017 (referred to as GOLD 2017), at mMRC Dyspnoea scale as following7:

\begin{tabular}{|c|c|}
\hline Grade & Grading of Breathlessness \\
\hline Grade 0 & I only get breathless with strenuous exercise \\
\hline Grade 1 & $\begin{array}{c}\text { I get short of breath when hurrying on level ground or walking up a } \\
\text { slight hill }\end{array}$ \\
\hline Grade 2 & $\begin{array}{l}\text { On level ground, I walk slower than people of the same age because of } \\
\text { breathlessness, or I have to stop for breath when walking at my own } \\
\text { pace on the level }\end{array}$ \\
\hline Grade 3 & $\begin{array}{l}\text { I stop for breath after walking about } 100 \text { yards or after a few minutes } \\
\text { on level ground }\end{array}$ \\
\hline Grade 4 & I am too breathless to leave the house or I am breathless when dressing \\
\hline
\end{tabular}

\section{Statistical Analysis}

Data was analyzed using computer software, Statistical Package for Social Sciences (SPSS). Analysis of variance was performed as parametric test to compare different variables. For all statistical evaluations, a two-tailed probability of value, $<0.05$ was considered significant. Data were expressed in its frequency and percentage.

\section{RESULTS}

166 patients who developed COPD were smoker accounting for $83 \%$ whereas non-smokers were 17 in number accounting for only $17 \%$. Cor pulmonale was found in 98 patients which is $49 \%$ of total enrolled patients. Acute coronary syndrome was found in 13 patients which is $6.5 \%$ of total enrolled patients. Arrhythmia was found only in 3 patient's accounting for $1.5 \%$ of total patients. Other cardiac complications included DCMP, restrictive cardiomyopathy and CHF was found only in 5 patients which is $2.5 \%$ of the total population. We found that 80 patients did not have any cardiac complication. We also observed that prevalence of smoking was high in all the groups. We found that among the males $89 \%$ were smoker whereas in females we found that prevalence was $34 \%$

When we compared patient with cor pulmonale to patients who did not manifest with any cardiac complication we found that mean PAP was $28.94 \mathrm{mmHg}$ for cor pulmonale group and $17.9 \mathrm{mmHg}$ for group without any cardiac complication and when we compared both the group we observed a $\mathrm{p}$ value of 0.0001 which is statistically very significant

We also found mean FEV1 \% predicted for group with cor pulmonale of $62.44 \%$ and $58.12 \%$ for patients without any cardiac complication and upon observing both the group we observed a p value of 0.0124 which is statistically significant.

We categorized all the patients according to duration of disease from its onset and found that in a period of up to 5 years 37 patients presented to us from COPD group which was $46 \%$ of their total no whereas for group COPD with Cor pulmonale 17 patients presented to us within 5 years of duration which is $17.3 \%$ of their total no. we also found that $6(46 \%)$ out of 13 patients were COPD with ACS (acute coronary syndrome), no patients with COPD with arrhythmia and 2 (40\%) patients presented with COPD with other cardiac complications. In the disease duration of $6-10$ years we found that the total no. $35(43.75 \%), 25$ (25.51\%), 6 (46.15\%), $2(66.66 \%)$ and $2(40 \%)$ for the groups COPD, COPD with Cor Pulmonale,

\begin{tabular}{|cccccc|}
\hline Category & Smoker & $\begin{array}{c}\text { Non- } \\
\text { Smoker }\end{array}$ & $\begin{array}{c}\text { Total } \\
\text { No. }\end{array}$ & $\begin{array}{c}\text { Percentage in } \\
\text { Total Patients }\end{array}$ & $\begin{array}{c}\text { Prevalence of } \\
\text { Smoking }\end{array}$ \\
Male & 130 & 15 & 145 & 77 & $89 \%$ \\
$\begin{array}{c}\text { Female } \\
\text { COPD with Cor }\end{array}$ & 36 & 19 & 55 & 33 & $34 \%$ \\
$\begin{array}{c}\text { Pulmonale } \\
\text { CAD }\end{array}$ & 10 & 15 & 98 & 49 & $84 \%$ \\
$\begin{array}{c}\text { Arrhythmia } \\
\text { Other cardiac } \\
\text { complication }\end{array}$ & 3 & 3 & 13 & 6.5 & $76 \%$ \\
$\begin{array}{c}\text { Patients without } \\
\text { any cardiac } \\
\text { complications }\end{array}$ & 65 & 1 & 5 & 2.5 & $80 \%$ \\
& & 15 & 80 & 40 & $81 \%$ \\
\hline
\end{tabular}

\begin{tabular}{|cccc|}
\hline Parameters & $\begin{array}{c}\text { COPD with } \\
\text { Cor Pulmonale }\end{array}$ & $\begin{array}{c}\text { COPD without Any } \\
\text { Cardiac Complication }\end{array}$ & P \\
Subjects & 98 & 80 & \\
Age (Mean \pm SD) & $61.11 \pm 12.11$ & $61.83 \pm 12.02$ & \\
Smoking history & 83 & 65 & 0.0001 \\
PAP (mmHg) (Mean \pm SD) & $28.94 \pm 4.61$ & $17.9 \pm 2.13$ & 0.0124 \\
FEV1 \% predicted & $62.44 \pm 11.49$ & $58.12 \pm 11.18$ & 0.13 \\
(Mean \pm SD) & & & \\
Table 2 Comparison between COPD with Cor pulmonale and COPD
\end{tabular}

Table 2. Comparison between COPD with Cor pulmonale and COPD without Any Cardiac Complication According to Different Parameters

\begin{tabular}{|cccccc|}
\hline & & & & \\
\end{tabular}

\begin{tabular}{|ccccc|}
\hline $\begin{array}{c}\text { ABCD } \\
\text { Criteria }\end{array}$ & $\begin{array}{c}\text { COPD with } \\
\text { Cor Pulmonale }\end{array}$ & mPAP & FEV1 & Pean \pm SD) \\
(Mean \pm SD) & P \\
A & $5(2.5 \%)$ & $23.2 \pm 3.70$ & $75.8 \pm 3.19$ & 0.0001 \\
B & $34(17 \%)$ & $26.23 \pm 3.64$ & $67.56 \pm 6.81$ & 0.0001 \\
C & $36(18 \%)$ & $30.58 \pm 03.44$ & $61.58 \pm 8.75$ & 0.0001 \\
D & $23(11.5 \%)$ & $31.6 \pm 0.69$ & $53.3 \pm 14.81$ & 0.0001 \\
Table 4. Classification of Patients with COPD with Cor pulmonale as \\
per GOLD Guidelines 2017 and Comparison of Mean PAP with Mean \\
FEV1 \% Predicted in Each Group \\
\hline \multicolumn{5}{c}{} \\
\hline
\end{tabular}

\begin{tabular}{|ccccc|}
\hline $\begin{array}{c}\text { ABCD } \\
\text { Criteria }\end{array}$ & $\begin{array}{c}\text { COPD with } \\
\text { Cor Pulmonale }\end{array}$ & $\begin{array}{c}\text { Mean Duration } \\
\text { of Disease }\end{array}$ & $\begin{array}{c}\text { FEV1 } \\
\text { (Mean } \pm \text { SD) }\end{array}$ & P \\
A & $5(2.5 \%)$ & $9.8 \pm 4.82$ & $75.8 \pm 3.19$ & 0.0001 \\
B & $34(17 \%)$ & $11.44 \pm 7.25$ & $67.56 \pm 6.81$ & 0.0001 \\
C & $36(18 \%)$ & $13.58 \pm 5.66$ & $61.58 \pm 8.75$ & 0.0001 \\
D & $23(11.5 \%)$ & $16.43 \pm 8.19$ & $53.3 \pm 14.81$ & 0.0001 \\
Table 5. Comparison of Mean PAP with Mean FEV1 \% Predicted in \\
Each Group in Patients with COPD with Cor pulmonale in Different \\
Groups as per GOLD Guidelines 2017 \\
\hline
\end{tabular}

COPD with ACS, COPD with arrhythmias and COPD with other cardiac complications respectively. For the disease duration between 11 to 15 for above respective group we found the total no 7 (8.75\%), 31 (31.63\%), 01 (7.69\%), 1 $(33 \%)$ and 1 (20\%) respectively for the group COPD, COPD with Cor Pulmonale, COPD with ACS, COPD with arrhythmias and COPD with other cardiac complications. For the duration of disease activity of 16 to 20 years of duration we found no. 
of patients $0,13(13.26 \%), 0,0$ and 0 for the group COPD, COPD with Cor pulmonale COPD with ACS, COPD with arrhythmias and COPD with other cardiac complications. For the duration of disease activity of more than 20 years we found $11(11.22 \%)$ in COPD with Cor pulmonale group and no patients in other groups.

We found that $5(2.5 \%)$ patients out of 98 patients with Cor pulmonale belonged to group A whereas 34, 36 and 23 patients belonged to group $\mathrm{B}, \mathrm{C}$ and $\mathrm{D}$. We found mPAP (mean \pm SD) for Group A, B, C, and D is $23.2 \pm 3.70,26.23 \pm$ $3.64,30.58$ ? 3.44 and $31.6 \pm 4.69 \mathrm{mmHg}$ respectively and mean \pm SD of FEV1 for Group A, B, C, and D is $75.8 \pm 3.19$, $67.56 \pm 6.81,61.58$ 0 8.75 and $53.3 \pm 14.81 \%$ predicted respectively. When we compared mean PAP and FEV1\% predicted in each group we observed $\mathrm{P}$ value of 0.0001 which is statically very significant.

We also found that mean duration for the patients in different groups according to ABCD criteria were 9.8 years for group A and 11.44, 13.58 and 16.43 for the groups B, C and D respectively and mean FEV1 in each group was 75.8\%, $67.56 \%, 61.58 \%$ and $53.3 \%$ predicted in respected group and we observed a P value of 0.0001 in each group upon comparing mean duration of disease with FEV1 in each group.

\section{DISCUSSION}

COPD is a very common lung disorder worldwide and in India. It tends to involve multiple systems including cardiac involvement which adds to the severity causing greater morbidity as well as mortality. Echocardiography has been a primary tool to evaluate the cardiac manifestation in COPD. Cor pulmonale was defined as "hypertrophy of the right ventricle resulting from diseases affecting the function and/or structure of the lungs except when these pulmonary alterations are the result of diseases that primarily affect the left side of the heart". Weitzenblum et al., (2003) ${ }^{[4]}$, have defined pulmonary hypertension on the basis of mean PAP and defined to be more than $20 \mathrm{mmHg}$ in cases secondary to lung disorders which is different from primary pulmonary hypertension where it has been defined to me more than 25 mmHg.

In our study we found that 166 patients who developed COPD were smoker accounting for $83 \%$ whereas nonsmokers were 17 in number accounting for only $17 \%$, The landmark cohort study of London men carried out by Fletcher and Peto (1977)[5] in the 1960s described the progressive decline of lung function with aging and the acceleration of this decline in smokers. In this study, smoking was the dominant determinant of decline beyond that expected from aging alone and infection did not affect the rate of decline. We also found that 98 (49\%) patient out of total 200 patients were diagnosed to have cor pulmonale using echocardiography as our primary tool and we categorized them using GOLD guidelines 2012 and found 82 (83\%) patients had moderate COPD whereas 13 (13.26\%) patients had severe COPD and $3(3.06 \%)$ patients had very severe COPD, higher incidence can be attributed to severity of the disease for which patients got admitted to our institution and cor pulmonale is more prevalent in more severe disease. We also found mPAP of $28.41 \mathrm{mmHg}$ for moderate COPD and $30.15 \mathrm{mmHg}$ and $38 \mathrm{mmHg}$ for severe and very severe COPD which shows a positive correlation between the severity of disease and pulmonary artery pressure. We also found that prevalence of Cor pulmonale was $45 \%$ in moderate COPD whereas it is $81 \%$ and $100 \%$ in severe and very severe disease.

The inverse relationship between FEV1 and pulmonary hypertension has been reported (Oswald-Mammoser et. al., 1991)[6] yet pulmonary hypertension can develop in those without significant resting hypoxemia. Severe emphysema with air-trapping and hyperinflation is associated with intrinsic positive end-expiratory pressure of $5-7.5 \mathrm{~cm} \mathrm{H} 2 \mathrm{O}$ (Tschernko et. al., 1998).[7]

N. K. Gupta, et al., (2011) ${ }^{[8]}$ have studied on the cardiac changes secondary to COPD by echocardiography and to find out the correlation between echocardiographic findings and severity of COPD. They found that, on echocardiographic evaluation of COPD, 50\% cases had normal echocardiographic parameters. The frequencies of $\mathrm{PH}$ in mild, moderate, severe, and very severe COPD were $16.67 \%$, $54.55 \%, 60.00 \%$, and $83.33 \%$, respectively. This was also seen in our study where we also found that prevalence of Cor pulmonale was $45 \%$ in moderate COPD whereas it is $81 \%$ and $100 \%$ in severe and very severe disease.

Finally resulted that the prevalence of $\mathrm{PH}$ has a linear relationship with severity of COPD and severe PH is almost associated with cor pulmonale. Echocardiography helps in early detection of cardiac complications in COPD cases giving time for early interventions. We also used ABCD criteria according to GOLD guidelines 2017 and found 27 (13.5\%) patients belonged to group A whereas 91 (45\%), 58 (29\%) and $24(12 \%)$ patients belonged to the group B, C and D. When we compared mean duration of disease with mean FEV1 \% predicted in each group we observed $P$ value of 0.0001 in each group suggestive of inverse relationship between duration of disease activity and FEV1.

D.A. Vakhlamov et al. (2016)[9] conducted a study in Russia on co relation with different risk factors and his results showed there duration of disease is strongly associated with development of disease and he found mean duration of disease was 10 year. He had also observed inverse relationship between FEV1 and development of cor pulmonale.

\section{CONCLUSIONS}

Utility of echocardiographic technique is to estimate mean PAP in patients with COPD of varying severity. Previously it has been demonstrated that Doppler echocardiography is sufficiently sensitive tool to measure changes in pulmonary arterial pressure.

In our study we also found that there is a positive correlation between the onset of disease and various complications and there is a higher prevalence of cor pulmonale as duration increases. There is directly proportional relation between mean PAP and duration of 
disease. Our study also shows inverse relation between mean PAP and FEV1; so, early detection of higher mean PAP can be very useful in determining the prognosis and disease outcome. The presented data shows that cor pulmonale is increasingly common with severity of COPD and also there is a statistically significant correlation of mean PAP with degree of COPD. Indeed, it has previously been suggested that loss of alveolar capillary bed surface area may contribute to the elevation of pulmonary arterial pressure associated with severe emphysema.

To conclude, the present study shows high prevalence of pulmonary hypertension, cor pulmonale, left ventricular dysfunction complicating COPD, more so with more severe COPD. We suggest screening of all COPD patients for cardiac complications. By estimating PAP early in the disease process even in those patients who are not able to perform lung function test correctly due to other co-morbidities such as altered mentation, poor learning ability and many other diseases, we can determine the prognosis of the disease and achieve a better outcome by planning more appropriate and intense line of management.

\section{REFERENCES}

[1] Fishman AP. State of the art: Chronic Cor Pulmonale. Am Rev Respire Dis 1976;114(4):775-94.
[2] World Health Report. Geneva: World Health Organisation, 2000. http://www.who.int/whr/2000/en/statistics.html.

[3] Simonneau G1, Galiè N, Rubin LJ, et al. Clinical classification of pulmonary hypertension. J Am Coll Cardiol 2004;43(12 Suppl S):5S-12S.

[4] Weitzenblum E. Chronic Cor Pulmonale. Heart 2003;89(2):225-30.

[5] Fletcher C, Peto R. The natural history of chronic airflow obstruction. Br Med J 1977;1(6077):1645-8.

[6] Oswald-Mammosser M, Weitzenblum E, Quoix E, et al. Prognostic factors in COPD patients receiving long-term oxygen therapy. Importance of pulmonary artery pressure. Chest 1995;107(5):1193-8.

[7] Tschernko EM, Gruber EM, Jaksch P, et al. Ventilatory mechanics and gas exchange during exercise before and after lung volume reduction surgery. Am J Respir Crit Care Med 1998;158(5 Pt 1):1424-31.

[8] Gupta NK, Agrawal RK, Srivastav AB, et al. Echocardiographic evaluation of heart in chronic obstructive pulmonary disease patient and its corelation with the severity of disease. Lung India 2011;28(2):105-9.

[9] Vakhlamov DA, Vakhlamov VA. Priority risk factors of developing Cor pulmonale in patients with chronic obstructive pulmonary disease according to correlation analysis findings. Clinical Medicine 2016;8(4):76-81. 